\title{
DETERMINING EFFECTIVE LENGTH FOR 40 HM-T STEEL BY USE OF NON-LOCAL LINE METHOD CONCEPT
}

\author{
Grzegorz Robak ${ }^{1}$ \\ Daniel Krzyżak ${ }^{1}$ \\ Artur Cichański \\ ${ }^{1}$ Opole University of Technology, Poland \\ ${ }^{2}$ UTP University of Science and Technology, Bydgoszcz, Poland
}

\begin{abstract}
In the paper, the concept of non-local line method is presented and used for determining the effective length for notched elements. Experimental tests and calculations were performed for $40 \mathrm{HM}-\mathrm{T}(42 \mathrm{CrMo4}+\mathrm{QT})$ steel made specimens of two types, i.e. smooth specimens, and notched specimens with notch radius equal to $0.2 \mathrm{~mm}, 0.5 \mathrm{~mm}, 0.8 \mathrm{~mm}$, and $1 \mathrm{~mm}$. The performed FEM calculations took into account the multi-linear hardening model and cyclic material properties. The concept of the presented non-local line method bases on finding the position of critical plane and determining the effective length, meant as the fracture process zone. During numerical stress gradient simulations, also the weight function was implemented. It was observed that the effective length increases as the load increases.
\end{abstract}

Keywords: weight function, effective length

\section{INTRODUCTION}

The fatigue phenomenon is very complex, and fatigue damage depends on many factors, such as the type and condition of the material, the geometry of the element, the type of load, and the state of stress [3, 9, 15, 21, 24]. Determining the fatigue life of notched elements is still a goal for many scientists [13, 16, 17]. Fatigue life calculation methods can be divided into local and non-local. In the local methods, only the effort at one point is considered, while the non-local methods, in contrast, take into account stress or strain gradients, and/or strain energy density. The fatigue life of notched elements can also be calculated using the Neuber fictitious radius method $[14,18,20,23]$, which can be perceived as a substitute of the non-local line method. In another work which deals with this method [11], the relation between the microstructural support length and the number of cycles of nominal stress is presented. The relation between the fracture process zone and the loading level is also presented in the papers which make use of the non-local volume method $[9,18]$. In those two papers, the variability of the fracture process zone is indicated for both the line method and the volume method. The known nonlocal methods assume that the effective length can depend on the notch radius $[12,16]$, the grain size [19], the plastic zone [22, 25], and the stress distribution [16]. The two first methods give good results only for brittle materials, while in the third method, also usually used for brittle materials, the critical plastic crack zone can be determined using the equation proposed by [7]

where:

$$
R_{y}=\mu \cdot\left(\frac{K_{I C}}{\sigma_{Y}}\right)^{2},
$$

$\mu$ - parameter which depends on loading condition,

$\mathrm{K}_{\mathrm{IC}}$ - fracture toughness,

$\sigma_{Y}-$ yield stress. 
Equation (1) can be converted and the critical distance $\mathrm{d}_{0}$ can be calculated from the equation

$$
d_{0}=\frac{\xi}{\pi} \cdot\left(\frac{K_{I C}}{\sigma_{Y}}\right)^{2},
$$

where:

$\xi$ - parameter determined based on author's research.

The main aspect of that approach was to determine the parameter $\xi$, because different values are proposed by different authors. The value of this parameter was determined based on experimental tests and simulations done for different materials, and it mainly depended on notch geometry.

Another way to determine the fracture process zone has been developed by [16]. This is a non-local volume method, nevertheless the effective distance concept can be meant as a part of the line methods. In that approach the authors made use of the effective distance to determine the fracture process zone, and then performed the calculations in this area. The effective distance was determined based on the relative stress gradient idea (Fig. 1).

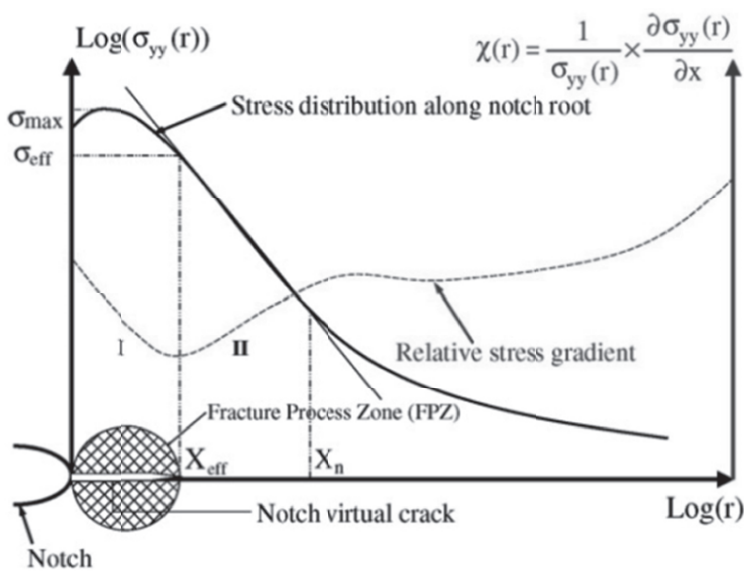

Fig. 1. Stress distribution and relative stress gradient [1]

The authors noticed that in the elasto-plastic calculation, the highest value of stress occurs at a certain distance behind the notch surface. It is usually observed for axial stress, maximum principal stress, but not for Huber-Mises-Hencky $(\mathrm{HMH})$ stress. For maximum principal stress, the minimum of the relative stress gradient is calculated from the equation

$$
\chi(r)=\frac{1}{\sigma_{y}(r)} \cdot \frac{d \sigma_{y y}(r)}{d r},
$$

where:

$\sigma_{\mathrm{yy}}-$ maximum principal stress,

$\mathrm{r}$ - radius in the calculation plane.

In order to obtain the proper relative stress gradient, the calculations should be done for the continuous function of stress, which allows to establish the inflexion point, the effective distance and, finally, the fracture process zone.

An additional aspect of making distinction between the mentioned non-local methods can be the method of stress calculation. Some authors perform stress calculations using the FEM method and elasto-plastic material properties $[6,8$, $10,16]$. This procedure requires the knowledge of the RambergOsgood equation parameters. The stress in the vicinity of the notch is known to be usually above the cyclic yield stress. Hence, determining the stress tensor is an important task, as it decides about the obtained effective lengths. The effective stress values can be calculated using the FEM method and the multi-linear hardening model. It provides good stress (effective stress) results, which can be in proper way compared with the values read from smooth specimen fatigue curves. Some non-local fatigue criteria base on the weight function, which makes it possible to take into account the meaning of different material layers during fatigue processes. In the literature, two interesting weight functions can be found [6, 8]. They are used in the area method, nevertheless they can be adopted to the line methods. In the method presented in [6], the weight function is equal to 1 for surface layers and for layers on which the maximum stress point occurs (Fig. 2 ). The weight function should include values within the interval $<0 \div 1>$ and should satisfy the following conditions:

$$
\left\{\begin{array}{l}
0 \leq \varphi(r, \chi) \leq 1 \\
Q(r=0, \chi(0))=1 \\
Q\left(r_{\max }, \chi\left(r_{\max }\right)\right)=1
\end{array} .\right.
$$

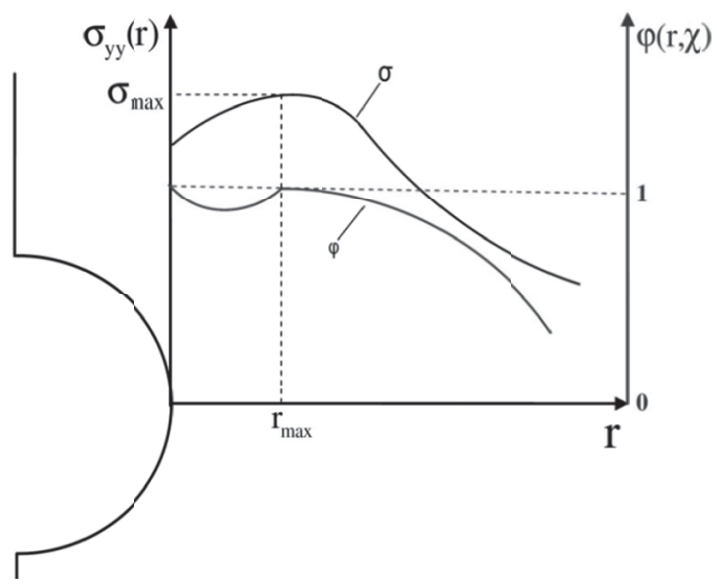

Fig. 2. Distribution of stress and weight function [1]

In [26], the authors describe the weight function as

$$
\varphi(r)=1-\left(1-\frac{\sigma_{e q}}{\sigma}\right) \cdot r(1-\sin (\theta)),
$$

where:

$\sigma_{e q}$ - equivalent stress,

$\sigma_{\text {max }}-$ maximum value of equivalent stress,

$\theta$ - angle of vector $r$.

According to this equation, the distance between the surface and the maximum effort point can be considered as the maximum effort area. Nevertheless, for the case of elastic condition, when the stress value is close to the cyclic yield 
stress, or when the plastic strain is very small, the weight function is equal to 1 only on the surface.

The weight function proposed in [8] (Fig. 3) is described as

$$
w(r)=e^{-\left(\frac{2 r}{l_{c}}\right)^{2}}
$$

where:

$\mathrm{r}$ - vector applied at the maximum effort point,

$l_{c}$ - critical length which determines the calculation area.

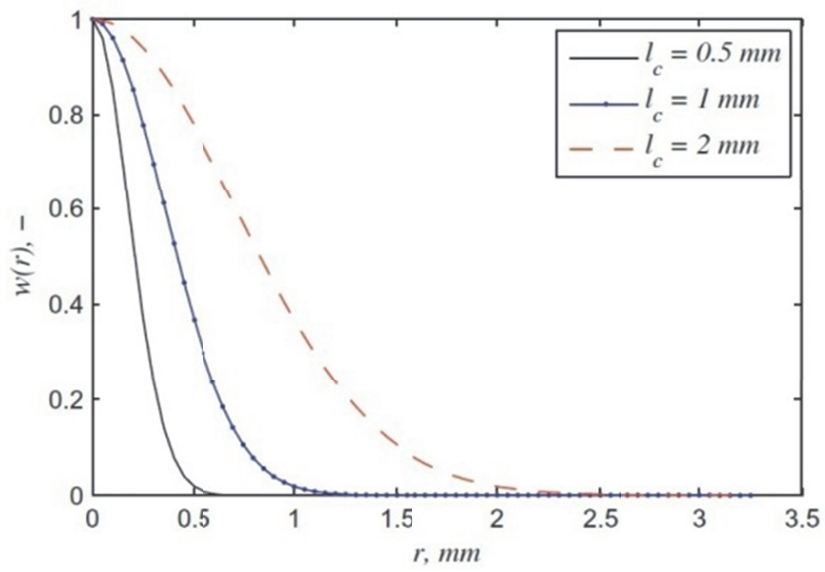

Fig 3. Weight function and different values of critical length [8]

Graphical representation of this weight function is the half plot of the normal Probability Density Function (PDF), where the critical length lc plays the main role.

According to the previously mentioned issues, the essence of the method presented in the article consists in finding the value of effective length. The presented model is a modification of three models $[6,8,16]$. It allows the calculation to be performed in the elastic or elasto-plastic state of strain.

\section{EXPERIMENTAL TESTS OF SMOOTH AND NOTCHED ELEMENTS}

In order to meet the requirements of the proposed model, a series of experimental tests had to be done. The available literature publications on the subject do not contain complete data necessary to perform the planned calculations. The performed experimental tests were expected to provide the data for smooth and notched specimens. For smooth specimens (Fig. 4), the experimental tests of the tensioncompression loading mode were performed. It allowed to determine the Wöhler fatigue curve and cyclic material properties. Mechanical properties of $40 \mathrm{HM}-\mathrm{T}$ (42CrMo4+QT) steel are presented in Table 1 , while its chemical composition is given in Table 2. The cyclic hardening coefficient $\mathrm{K}^{\prime}$ and the cyclic hardening exponent n' are material constants, which were used to describe the cyclic hardening curve in the FEM analysis. Strains were measured with the aid of an extensometer, which allowed to record a hysteresis loop. The fatigue tests were done with force control. The obtained fatigue curve is presented in Fig. 5. The specimens were made according to the Polish Standard PN-84/H-04308, and the tests were performed according to the standards ASTM 739-80.
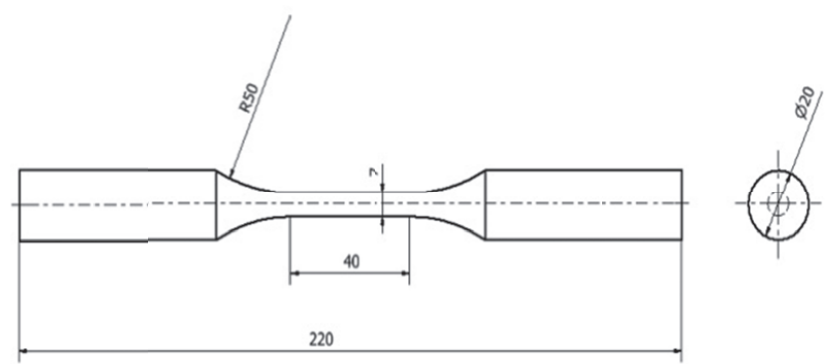

Fig. 4. Geometry of smooth specimen

Tab. 1. Mechanical properties of $40 \mathrm{HM}-\mathrm{T}$ (42CrMo4+QT) steel

\begin{tabular}{|c|c|c|c|}
\hline $\begin{array}{c}\text { Young's } \\
\text { modulus E, } \\
\text { GPa }\end{array}$ & $\begin{array}{c}\text { Poisson's } \\
\text { coefficient } v,-\end{array}$ & $\begin{array}{c}\text { Static yield } \\
\text { strength } \sigma_{\mathrm{Y}}, \mathrm{MPa}\end{array}$ & $\begin{array}{c}\text { Ultimate tensile } \\
\text { strength } \sigma_{\text {UTS }} \\
\mathrm{MPa}\end{array}$ \\
\hline 210 & 0.31 & 1074 & 1170 \\
\hline $\begin{array}{l}\text { Cyclic yield } \\
\text { strength } \sigma_{\mathrm{Y}} \text {, } \\
\mathrm{MPa}\end{array}$ & $\begin{array}{c}\text { Cyclic hardening } \\
\text { coefficient K, } \\
\mathrm{MPa}\end{array}$ & $\begin{array}{l}\text { Cyclic hardening } \\
\text { exponent n', - }\end{array}$ & \\
\hline 600 & 1750.5 & 0.095 & \\
\hline
\end{tabular}

Tab. 2. Chemical composition of $40 \mathrm{HM}-\mathrm{T}$ (42CrMo4+QT) steel (Fe the rest)

\begin{tabular}{|c|c|c|c|c|}
\hline $\mathrm{C}$ & $\mathrm{Mn}$ & $\mathrm{Si}$ & $\mathrm{P}$ & $\mathrm{S}$ \\
\hline 0.44 & 0.77 & 0.27 & 0.011 & 0.008 \\
\hline $\mathrm{Cr}$ & $\mathrm{Ni}$ & $\mathrm{Cu}$ & $\mathrm{Mo}$ & $\mathrm{Al}$ \\
\hline 1.18 & 0.12 & 0.19 & 0.18 & 0.022 \\
\hline
\end{tabular}

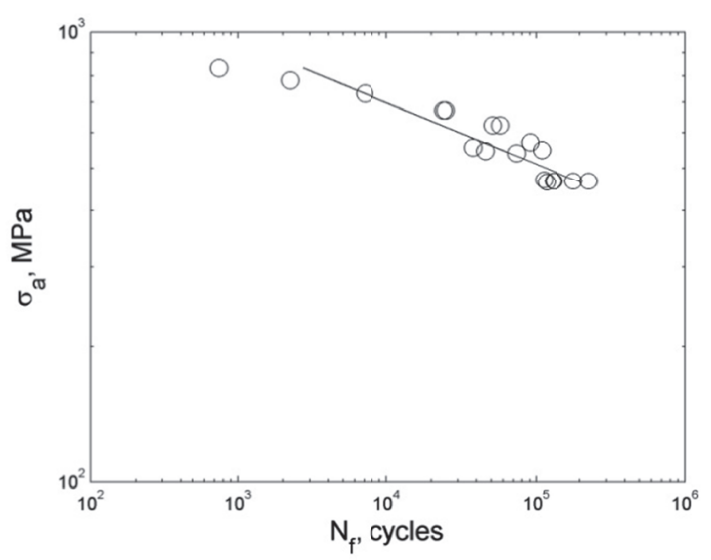

Fig. 5. Smooth specimen fatigue curve

The next series of experimental tests were performed with notched specimens subjected to cyclic bending. In order to compare different stress values at notch tip and the influence of the stress gradient on the number of cycles before crack initiation, two types of notch radius in the tested specimens were applied (Fig. 6). The values of the notch radius $\mathrm{R}$ in the 
specimen were respectively equal to $0.2 \mathrm{~mm}, 0.5 \mathrm{~mm}, 0.8$ $\mathrm{mm}$, and $1 \mathrm{~mm}$.
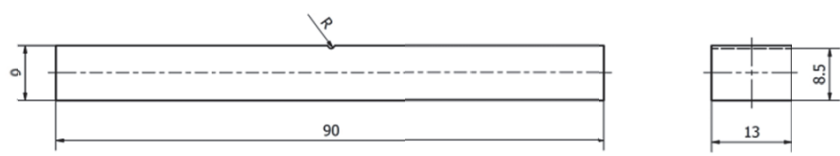

Fig. 6. Geometry of notched specimen

The crack length of $0.1 \mathrm{~mm}$ was assumed as the criterion of crack initiation. This value was accepted bearing in mind the camera capacity which enabled cracks of this length to be observed first. To create the Wöhlers fatigue curves, the number of cycles before crack initiation and the stress values calculated by the FEM code were used. Due to a complex state of stress at notch tip, the stress values were calculated according to the HMH hypothesis. Details of calculations are presented in the next chapter. Figure 7 shows the Basquin characteristics determined for smooth and notched specimens, for $\mathrm{R}=0.5 \mathrm{~mm}$ and $1.0 \mathrm{~mm}$ and for the cycle number between 104 and 106. The calculated linear regression coefficients of the equation are presented in Table 3.

$$
\log N_{f}=A-m \cdot \log \sigma_{a}
$$

where:

A and $\mathrm{m}$ - constants of the regression model.

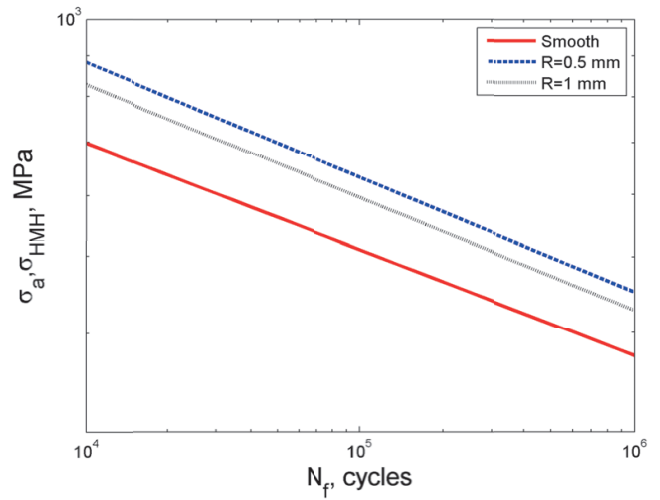

Fig. 7. Basquin fatigue curves for smooth and notched specimens

Tab. 3. Linear regression coefficients for smooth and notched specimens

\begin{tabular}{|c|c|c|}
\hline Type of specimen & $\mathrm{A},-$ & $\mathrm{m},-$ \\
\hline Smooth & 25.02 & 7.39 \\
\hline $\begin{array}{c}\text { Notched, } \\
\mathrm{R}=0.2 \mathrm{~mm}\end{array}$ & 22.56 & 6.11 \\
\hline $\begin{array}{c}\text { Notched, } \\
\mathrm{R}=0.5 \mathrm{~mm}\end{array}$ & 24.201 & 6.85 \\
\hline $\begin{array}{c}\text { Notched, } \\
\mathrm{R}=0.8 \mathrm{~mm}\end{array}$ & 22.70 & 6.40 \\
\hline $\begin{array}{c}\text { Notched, } \\
\mathrm{R}=1 \mathrm{~mm}\end{array}$ & 24.37 & 6.98 \\
\hline
\end{tabular}

\section{FINITE ELEMENT METHOD CALCULATIONS}

The performed calculations have the form of static nonlinear analysis making use of the multi-linear hardening model. This type of calculations requires a powerful computer, due to a large number of elements in the solid model. Since the width of the specimen was relatively large, compared to its height, the plane strain state was used in the FEM analysis. Nevertheless, the calculations were also performed for the plane stress state. The obtained relation between effective length and nominal stress, and the comparison between the experimental and calculated fatigue life, are similar to those obtained in the plane strain state. Cyclic material properties and the multi-linear hardening model for $40 \mathrm{HM}-\mathrm{T}$ (42CrMo4+QT) steel are presented in Figure 8. The analyses were conducted in the ANSYS software environment, making use of the second order 8-nodes 2D element PLANE183. The influence of the order of element on the accuracy of FEM analysis of notched specimens was checked in [3]. The accuracy of FEM notch models depends not only on the characteristic mesh size [5], but also on mesh morphology [4]. To ensure control of the notch root element shape, mapped meshes with circular sub-areas [4] were used (Fig. 9). The characteristic mesh size near the notch root was $0.033 \mathrm{~mm}$, while that for the remaining part of the specimen was $0.1 \mathrm{~mm}$.

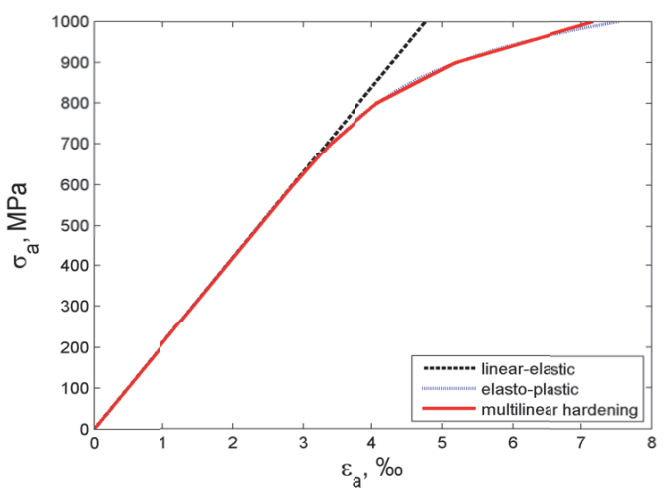

Fig. 8. $\sigma_{a}-\varepsilon_{a}$ relations for $40 \mathrm{HM}-\mathrm{T}$ steel

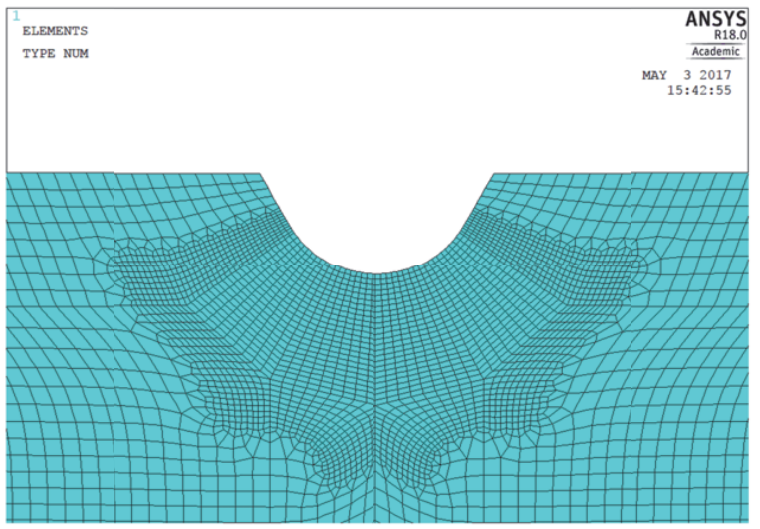

Fig. 9. Mesh structure near notch root for specimen $R=0.5 \mathrm{~mm}$ 
Selected sample results of the notched specimen analysis for $\mathrm{R}=0.5 \mathrm{~mm}$ and $1 \mathrm{~mm}$, and for the same loading level (nominal stress equal to $402.5 \mathrm{MPa}$, are shown in Fig. 10.

a)

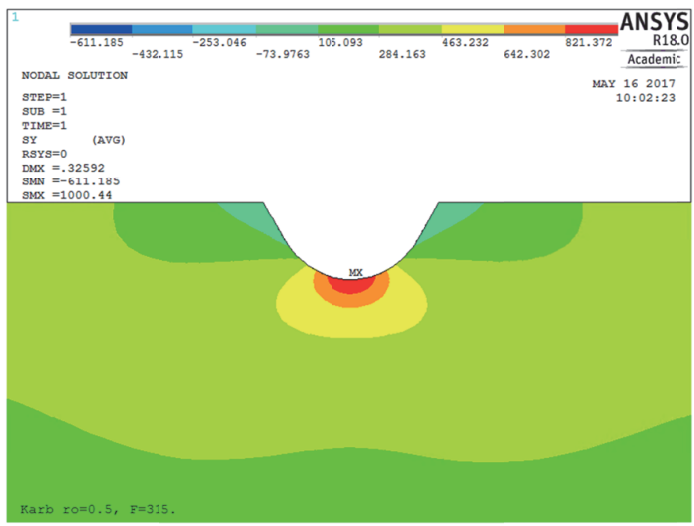

b)

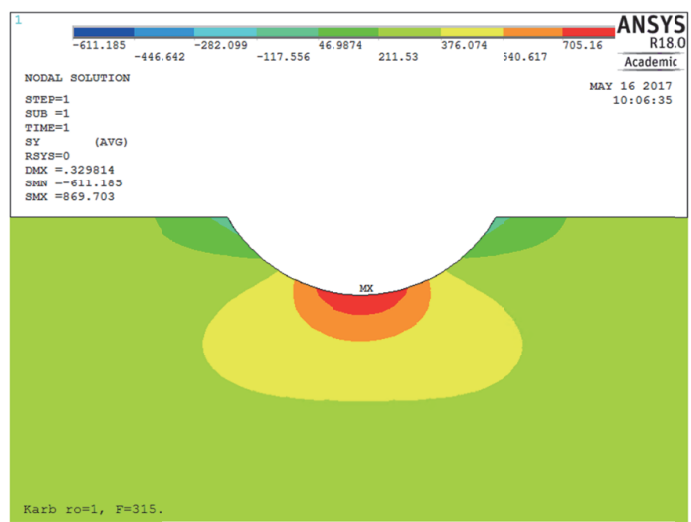

Fig. 10. Results of FEM analysis for notched specimens with a) $R=0.5 \mathrm{~mm}\left(\sigma_{y}\right.$ stress, $M P a)$ and $b$ ) $R=1 \mathrm{~mm}\left(\sigma_{y y}\right.$ stress, $\mathrm{MPa}$ )

Changes of stresses $\sigma_{\text {уу }}$ and $\sigma_{\text {нмн }}$ along the plane perpendicular to the specimen axis (predicted critical plane) are shown in Fig. 11.

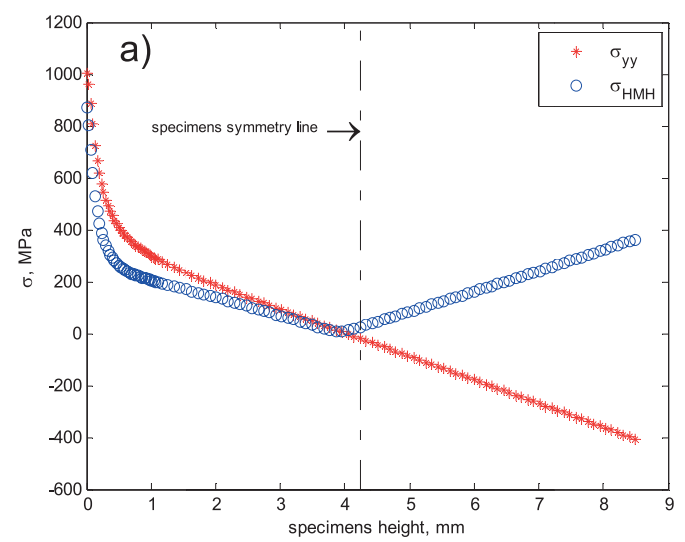

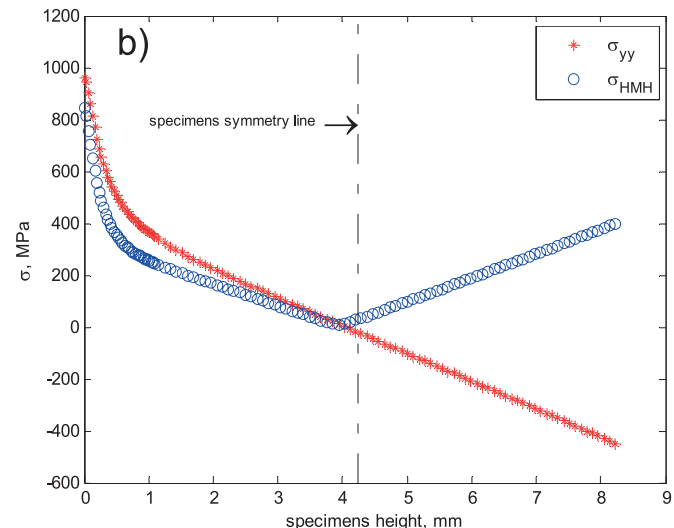

Fig. 11. Values of stresses $\sigma y y$ and $\sigma H M H$ along the plane perpendicular to the specimen symmetry axis, for a) $R=0.5 \mathrm{~mm}$ and $b$ ) $R=1 \mathrm{~mm}$

\section{CONCEPT OF NON-LOCAL LINE METHOD}

As mentioned in Introduction, non-local line methods base on determining the fracture process zone, which is represented by some length. The main rule is that this zone should contain the highest stress region. The first task in this method is to determine the critical plane in which the calculation should be done. The critical plane is determined under an assumption that the crack initiation starts on the notch tip surface and then propagates in a plane where the normal stress is the highest. It has been proved experimentally that the crack initiation point is very close to the point at which the maximum value of HMH stress is recorded. Due to this fact, the position of the critical plane is determined by the point on the surface where HMH stress has the maximum value. This is well justified, as at this point the multi-axial state of stress is the highest and crack initiation most likely. Hence, at this point the critical plane is determined according to the equation

$$
\sigma_{\eta}=\sigma_{i j} \cdot n_{j},
$$

where:

$$
\begin{aligned}
& \sigma \text { - stress, } \\
& \eta \text { - position of the plane, } \\
& n \text { - vector normal to the surface, }
\end{aligned}
$$

The position of the critical plane is determined in the established coordinate system in which the $\mathrm{x}$-axis is parallel to the roll axis of the specimen and the angle is measured in the yz-plane (Fig. 12).

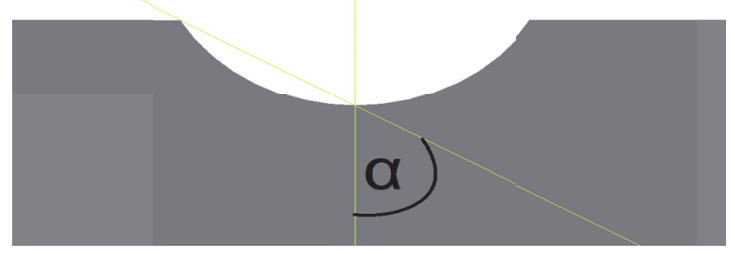

Fig. 12. Principle of critical plane position measurement 
The next step was to interpolate stress values in the defined plane and calculate stresses according to Eq. (8). It was done using the interpolation method available in the Matlab software. The interpolated gradient of stress $\sigma_{\eta}$ was then averaged according to the equation

$$
\sigma_{e q}=\frac{1}{\int_{0}^{l_{e f}} Q d l} \cdot \int_{0}^{l_{e f}} \sigma_{\eta} \cdot Q d l,
$$

where:

$\sigma_{e q}$ - equivalent failure stress,

$Q$ - weight function,

$l_{e f}$ - effective length.

The effective length $l_{e f}$ is the scope at which averaging is performed. The used weight function $Q$ bases on the assumption proposed in [8]. Physical meaning of the weight function is that it takes into account weights of particular layers in the fracture process. It represents a half of the normal PDF and it has values between $0 \div 1$. However, in cases of greater plastic strain, the stress has the maximum at a certain distance below the surface. It means that the highest stress point has the weight smaller than 1 . Hence, some modification of the weight function was proposed, in which the layers between the element surface and the plane of highest stress point $\sigma_{\eta}$ have also the weights equal to 1 . It is described by the following formula

$$
\begin{aligned}
& Q=1 \text { for } 0 \leq l<l_{\sigma_{\eta, \text { max }}} \\
& Q=e^{-\left(\frac{2 \cdot\left(l=l_{\sigma_{\eta, \max }}\right)}{l_{e f}}\right)^{2}} \text { for } l \geq l_{\sigma_{\eta, \text { max }}},
\end{aligned}
$$

where:

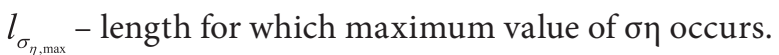

For smooth specimens without stress gradient, $l_{e f}$ is equal to 0 and the weight of each layers is equal to 1 . The weight function and the stress distributions are shown in Fig. 13. The length $l_{e f}$ is determined using the numerical iteration process done by a special programmed script. The iteration point for which $\sigma_{e f}$ has greater value than the stress in the smooth specimen for the same number of cycles is the inflexion point, which determines the value of $l_{e f}$ It is important to notice that the obtained values of $l_{e f}$ can differ depending on the loading level.

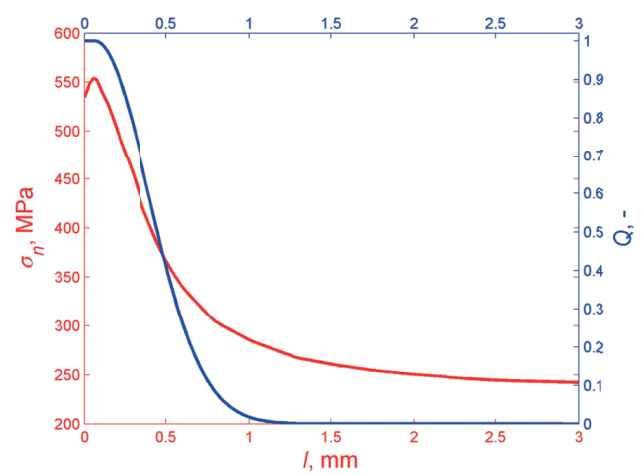

Fig. 13. Sample stress and weight function distributions along length

\section{ANALYSIS OF RESULTS}

A set of final values of $l_{\text {ef }}$ can be presented as a function of bending nominal stress $\sigma_{\text {nom }}$. It clearly shows the relation between the loading level and $l_{e f}$ The results for two notch radius values are presented in Fig. 14 and Fig. 15. Additionally, linear regression was done based on the obtained points. It can be seen that the relation between $l_{e f}$ and $\sigma_{n o m}$ is linear.

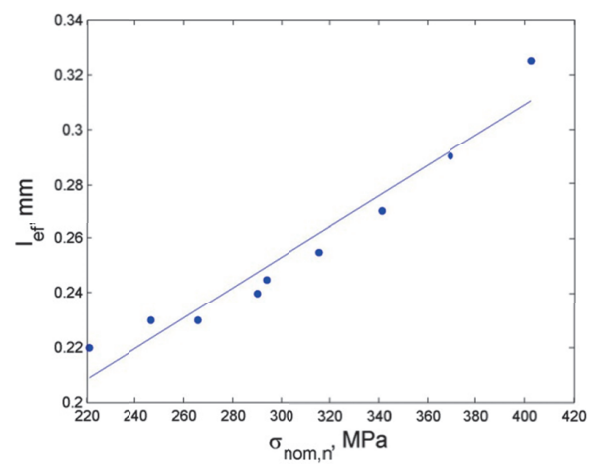

Fig. 14. Relation between effective length and nominal stress for notched specimen with $R=0.5 \mathrm{~mm}$. Correlation coefficient $r=0.989$

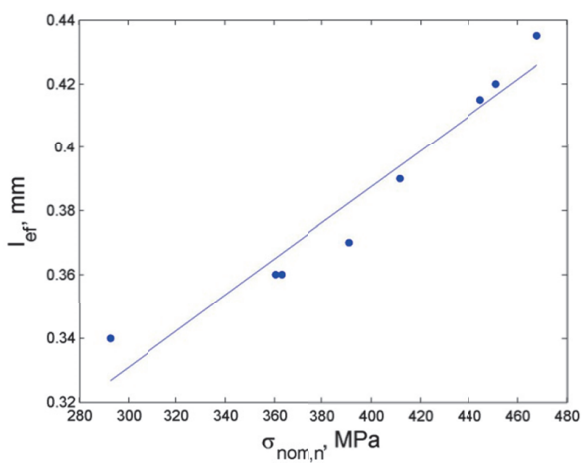

Fig. 15. Relation between effective length and nominal stress for notched specimen with $R=1 \mathrm{~mm}$. Correlation coefficient $r=0.982$

The effective length dependence on both nominal stress and stress concentration factors can be represented by a plane (Fig. 16). The values of stress concentration factor $k_{t}$ for different specimen geometries are presented in Table 4. Based on the results of calculations for $40 \mathrm{HM}-\mathrm{T}$ (42CrMo4+QT) steel, the plane equation can be established using multiple regression and 95\% confidence bounds (the design curve based on $95 \%$ lower confidence limits).

Tab. 4. Values of stress concentration factor $k_{t}$ for notched specimens

\begin{tabular}{|c|c|c|c|c|}
\hline $\begin{array}{c}\text { Type of } \\
\text { specimen }\end{array}$ & $\mathrm{R}=0.2 \mathrm{~mm}$ & $\mathrm{R}=0.5 \mathrm{~mm}$ & $\mathrm{R}=0.8 \mathrm{~mm}$ & $\mathrm{R}=1.0 \mathrm{~mm}$ \\
\hline$k_{t}$ & 3.7 & 2.6 & 1.8 & 1.4 \\
\hline
\end{tabular}




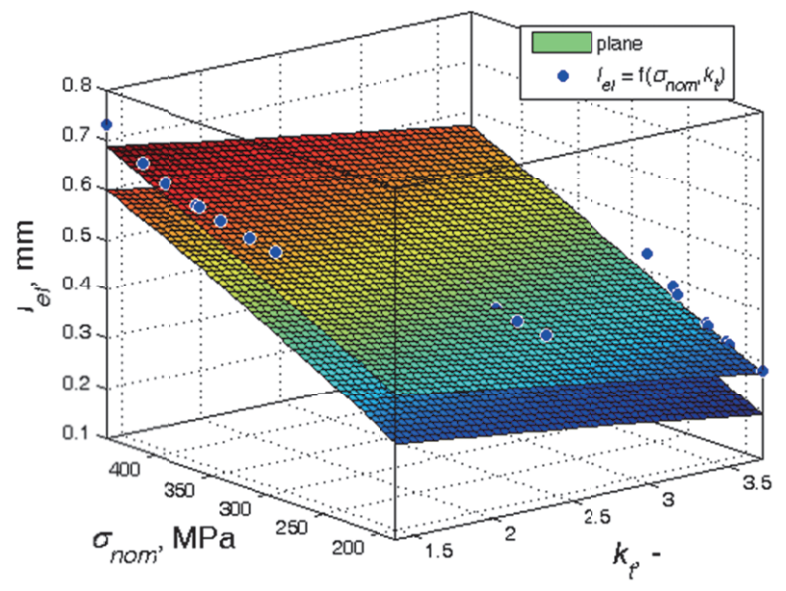

Fig. 16. Relation of effective length with stress concentration factor and nominal stress for $40 \mathrm{HM}-\mathrm{T}(42 \mathrm{CrMo} 4+\mathrm{QT})$ steel notched specimen

Based on the calculated values of effective lengths, the plane equation for $95 \%$ lower confidence limit has the form:

$$
l_{\text {ef }}=-0.496 \cdot k_{t}+0.0011 \cdot \sigma_{\text {nom }}+0.16 .
$$

A comparison between the calculated and experimental fatigue life for the cycle number ranging between $10^{4}$ and $10^{6}$ is given in Fig. 17 and 18. It can be noticed that in each case the scatter is smaller than 3 . This scatter results from the use of linear regression in the fatigue curves and in the function $l_{\text {ef }}=f\left(\sigma_{\text {nom }}, k_{t}\right)$.

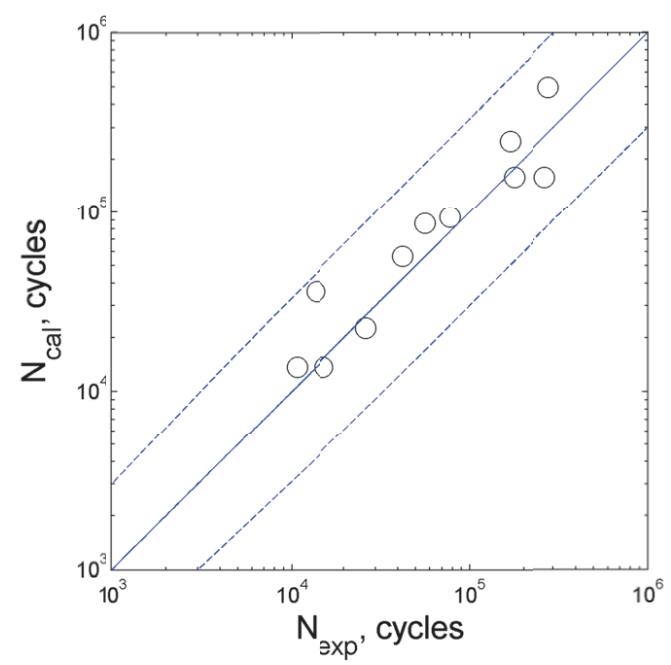

Fig. 17. Comparison between experimental and calculated fatigue life for notched specimens with $R=0.5 \mathrm{~mm}$

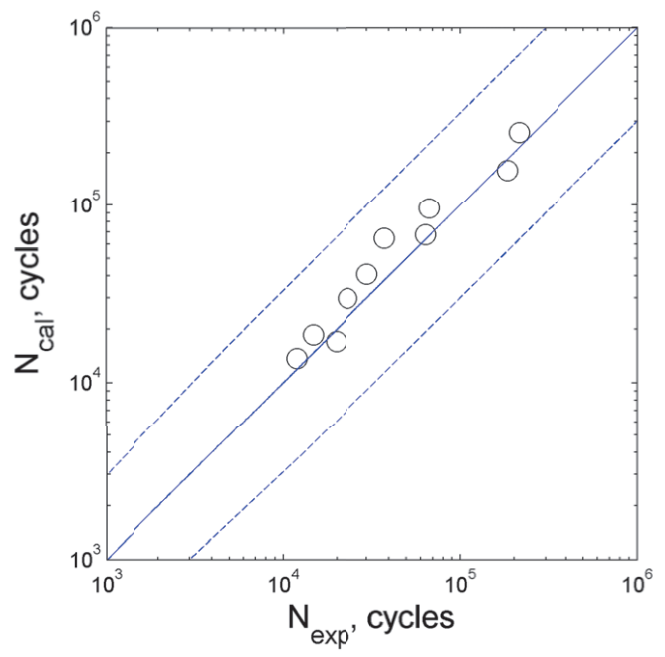

Fig. 18. Comparison between experimental and calculated fatigue life for notched specimens with $R=1 \mathrm{~mm}$

It is clear that from an engineering point of view, one constant value of $1_{\text {ef }}$ is desirable. Analysing the calculated values of lef, the smallest value can be considered conservative. However, the range of stress calculated by the FEM code should also be mentioned. For the performed research, $1_{\text {ef }}$ can be equal to $0.21 \mathrm{~mm}$ for the local effective stress ranging between $200 \div 450 \mathrm{MPa}$.

\section{CONCLUSIONS}

In non-local methods, the most important issues refer to proper determination of the fracture process zone and the equivalent stress. The stress distribution calculated in the elasto-plastic range differs from that calculated in the elastic range, which leads to different values of effective length. The other important issue is determining the plane in which the calculations are to be done. This plane should comply with the experiment. Based on the performed experimental tests and numerical simulations, the following main conclusions can be listed:

1. The position of the critical plane has been determined at the point where the multiaxial state of stress is the greatest.

2. The calculated position of the critical plane complies with that observed during fatigue tests.

3. The normal stress calculated in the defined plane has been established to be responsible for fracture.

4. In the notched element, a sub-area has been indicated between the outer surface of the element and the place at which the normal stresses reach the maximum. The normal stress values in this sub-area have the greatest impact on the effective length value.

5. The calculated effective length is not a constant value. The effective length increases as the load increases, but decreases when the stress concentration factor increases. 


\section{REFERENCES}

1. Adib-Ramezani H., Jeong J., Advanced volumetric method for fatigue life prediction using stress gradient effects at notch roots, Computational Materials Science, 39 (2007) 649-663.

2. Carpinteri A, Spagnoli A., Vantadori S., Viappiani D., A multiaxial criterion for notch high-cycle fatigue using a critical-point method, Engineering Fracture Mechanics 75 (2008) 1864-1874.

3. Cichański A., Influence of finite element order on SCF precision for $U$-shaped notches in flat bars under tension, Proceedings of 17th International Conference on Engineering Mechanics 2011, Svratka-Czech Republic, (2011) 79-82.

4. Cichański A., The influence of mesh morphology on the SCF in 2D FEM analysis of flat bars with opposite V-notch under tension, Proceedings of 22nd International Conference on Engineering Mechanics 2016, Svratka-Czech Republic, (2016) 110-113.

5. Cichański A., Mesh size dependency on notch radius for FEM analysis of notched round bars under tension, AIP Conference Proceedings 1822, 020004 (2017).

6. De-Guang Shang, Da-Kang Wang, Ming Li, Wei-Xing Yao, Local stress-strain field intensity approach to fatigue life prediction under random cyclic loading, International Journal of Fatigue, 23 (2001) 903-910.

7. Irwin G., Analysis of stresses and strains near the end of a crack traversing a plate, Journal of Applied Mechanics, 24 (1957) 361-364.

8. Karolczuk A., Blacha Ł., Fatigue life estimation under variable amplitude bending using the non-local damage parameter and multisurface plasticity model, International Journal of Fatigue 33 (2011) 1376-1383.

9. Kluger K., Łagoda T., Fatigue life estimation for selected materials in multiaxial stress states with mean stress, Journal of theoretical and applied mechanics, 54 (2016) 385-396.

10. Krzyżak D., Lagoda T., Fatigue life estimation of notched elements with use of non-local volumetric method, International Journal of Fatigue, Vol. 61 (2014) 59-66.

11. Krzyżak D., Robak G., Łagoda T., Determining fatigue life of bent and tensioned elements with a notch, with use of fictitious radius, Fatigue and Fracture of Engineering Materials and Structures, 38 (2015) 693-699.
12. Krzyżak D., Robak, G., Łagoda, T., Non-local line method with weight function and critical plane approaches used for fatigue life calculation of notched elements, Fatigue and Fracture of Engineering Materials and Structures Vol. 40, 2017.

13. Łagoda, T., Robak, G. and Słowik, J., Fatigue life of steel notched elements including the complex stress state. Materials and Design, 51 (2013) 935-942.

14. Neuber H., Über die Berücksichtigung der Spannungskonzentration bei Festigkeitsberechnungen, Konstruktion im Maschinen-Apparatte und Gerätebau, Heft 7 (1968) 245-251.

15. Pawliczek R., Kluger K., Influence of irregularity coefficient of loading on calculated fatigue life, Journal of Theoretical and Applied mechanics, 51 No. 4 (2013).

16. Pluvinage G., Fracture and fatigue emanating from stress concentrators, Kluwer, Dordrecht (2003).

17. Radaj D, Vormwand M., Advanced methods of fatigue assessment. Springer Verlag Berlin Heidelberg (2013).

18. Radaj D., Lazzarin P., Berto F., Generalised Neuber concept of fictitious notch rounding, International Journal of Fatigue, Vol. 51 (2013) 105-115.

19. Ritchie RO., Knott JF., Rice JR., On the relationship between critical tensile stress and fracture toughness in mild steel, Journal of the Mechanics and Physics of Solids, 21 (1973) 359-410.

20. Robak G., Szymaniec M., Lagoda T., The fictitious radius as a tool for fatigue life estimation of notched elements, Materials Science Forum, 726 (2012) 27-32.

21. Rozumek D., Marciniak Z., Fatigue properties of notched specimens made of FeP04 steel. Materials Science, 47(4) (2012) 462-469.

22. Seweryn A., Brittle fracture criterion for structures with sharp notches, Engineering Fracture Mechanics, 47 (4) (1994) 673-681.

23. Sonsino C.M., Łagoda T., Assessment of multiaxial fatigue behaviour of welded joints under combined bending and torsion by application of a fictitious notch radius, International Journal of Fatigue, 26 (2004) 265-279.

24. Szala G. Comments on linear summation hypothesis of fatigue failures, Polish Maritime Research 3(83) Vol. 21, (2014)

25. Taylor D., Predicting the fracture strength of ceramic materials using the theory of critical distances, Engineering 
Fracture Mechanics, 71 (2004) 2407-2416.

26. Yao W., Ye B., Zheng L. A verification of the assumption of anti-fatigue design, International Journal of Fatigue, 23 (2001) 271-277

\title{
CONTACT WITH THE AUTHOR
}

\author{
Grzegorz Robak \\ e-mail:g.robak@po.opole.pl \\ Opole University of Technology \\ Mikołajczyka St. 5 \\ 45-270 Opole \\ Poland \\ Daniel Krzyżak \\ e-mail:d.krzyzak@doktorant.po.edu.pl \\ Opole University of Technology \\ Mikołajczyka St. 5 \\ 45-270 Opole \\ Poland \\ Artur Cichański \\ e-mail:artur.cichanski@utp.edu.pl \\ UTP University of Science and Technology \\ Al. prof. S. Kaliskiego 7 \\ 85-796 Bydgoszcz \\ Poland
}

